\title{
Sustentabilidade em questão: Lições acerca do Ro mpimento da Barragem em Mariana (MG, 2015)
}

Sustainability in question: Lessons about the Dam Burst in Mariana (MG, 2015)

Sostenibilidad en cuestión: Lecciones sobre la Rompimiento de la Represa en

Mariana (MG 2015)

Durabilité en question: Leçons sur la Rupture du Barrage à Mariana (MG, 2015)

\section{Leandro Dias de Oliveira}

\section{(2) OpenEdition}

Journals

Edição electrónica

URL: http://journals.openedition.org/espacoeconomia/4041

DOI: $10.4000 /$ espacoeconomia.4041

ISSN: 2317-7837

Editora

Núcleo de Pesquisa Espaço \& Economia

Refêrencia eletrónica

Leandro Dias de Oliveira, « Sustentabilidade em questão: Lições acerca do Rompimento da Barragem em Mariana (MG, 2015) », Espaço e Economia [Online], 13 | 2018, posto online no dia 19 novembro 2018, consultado o 19 abril 2019. URL : http://journals.openedition.org/espacoeconomia/4041 ; DOI : 10.4000/espacoeconomia.4041

Este documento foi criado de forma automática no dia 19 Abril 2019.

(c) NUPEE 


\section{Sustentabilidade em questão: Lições acerca do Rompimento da Barragem em Mariana (MG, 2015)}

Sustainability in question: Lessons about the Dam Burst in Mariana (MG, 2015)

Sostenibilidad en cuestión: Lecciones sobre la Rompimiento de la Represa en

Mariana (MG 2015)

Durabilité en question: Leçons sur la Rupture du Barrage à Mariana (MG, 2015)

Leandro Dias de Oliveira

\section{NOTA DO AUTOR}

Este paper é fruto de uma conferência realizada por ocasião da I JUCONS - Primeira Jornada Universitária de Conflitos Socioambientais, no auditório do Pavilhão de Aulas Teóricas da UFRRJ - Universidade Federal Rural do Rio de Janeiro, campus Seropédica Rio de Janeiro, em 05 de novembro de 2018. Este evento, organizado por alunos de diferentes cursos da UFRRJ - Geografia, Geologia, Agronomia, Engenharia Florestal, Economia, Ciências Sociais, Serviço Social e Direito -, foi articulado em âmbito nacional com outras instituições públicas de nível superior com a finalidade de refletir, após exatos três anos do desastre ambiental de Mariana - MG, acerca dos conflitos socioambientais tão comuns na contemporaneidade. Agradeço o convite da Comissão Organizadora para que pudesse contribuir com tão importante debate.

\section{Introdução}

1 Três anos. Foi exatamente em 05 de novembro de 2015 que se rompeu uma barragem de rejeitos de mineração controlada pela Samarco Mineração S.A. e deixou um rastro de destruição por vários lugares - registre-se a completa obliteração do subdistrito de Bento 
Rodrigues, na cidade de Mariana -, percorreu as águas do Rio Doce e atingiu o Oceano Atlântico. Trata-se do maior impacto ambiental da história brasileira e o maior do mundo envolvendo barragens de rejeitos, com um volume total despejado de 62 milhões de metros cúbicos ${ }^{1}$, cujos malefícios ambientais são de fato imensuráveis.

2 O objetivo deste artigo não é de fato realizar uma análise espectral sobre este triste episódio ambiental brasileiro, mas extrair lições, sob o olhar crítico da Geografia, dos fatos já conhecidos e plenamente verificados e volatilizados pela máquina de moer notícias e fabricar informações da atualidade. Afinal, vivemos tempos de grande velocidade de descarte de notícias, por meio "brincadeiras", "testes" e "memes" em redes sociais, onde são criadas, repetidas, saturadas e esquecidas; acreditamos que uma sociedade que volatiza tão rápido a informação certamente se torna incapaz de compreendê-la.

3 Assim, dividimos esta análise em duas partes: a primeira, intitulada Apontamentos Preliminares: Notas sobre a questão ambiental contemporânea, apresenta os marcos teóricos da discursão sobre a problemática ecológica e seus atuais desafios; a segunda, intitulada $A$ geografia de um desastre e as lições de uma tragédia, revela o esforço de extrair seis lições, ao mesmo tempo duras e necessárias, em meio a tempos de desenvolvimento excludente e barbárie político-ambiental.

\section{Apontamentos Preliminares: Notas sobre a questão ambiental contemporânea}

4 "Cientistas encontraram a primeira evidência de que partículas de poluição do ar viajam pelos pulmões de mulheres grávidas e se alojam em suas placentas", é o que aponta uma recém-publicada reportagem no jornal inglês The Guardian². As evidências de que o ar tóxico circula através dos corpos das mães foram demonstradas em pesquisas desenvolvidas na Queen Mary University of London. No congresso internacional da European Respiratory Society's (ERS), em Paris [Setembro/2018], a Dr.. Lisa Miyashita reforça que já havia evidências de que a poluição era capaz de causar enorme redução na inteligência devido à presença de nanopartículas tóxicas da poluição do ar em cérebros humanos; mas ao apontar os perigos da poluição para bebês em gestação por meio de contaminação por partículas de fuligem capazes de atingir a placenta através da corrente sanguínea ${ }^{3}$, conforme apontado no jornal também britânico The Independent, comprovase que assim como as nefastas bombas nucleares a poluição tem impacto nas gerações presente e futura.

5 A referência à eclosão das bombas nucleares ao fim da Segunda Grande Guerra não é meramente simbólica: são tais artefatos de destruição descomunal que propiciaram a certeza da capacidade de destruição macroescalar dos países mais poderosos e substanciaram a emersão das preocupações ambientais contemporâneas ${ }^{4}$. Afinal, a explosão das bombas atômicas em território japonês elucidou para todos que não havia limites para as ambições de poder na sociedade humana e ainda deixou patente tratar-se de uma ameaça real às gerações futuras, uma vez que tais armamentos nucleares destroem por completo o lugar de sua detonação, extinguindo a vida presente e comprometendo a sua descendência devido à radiação.

6 Foi sintomático que a partir de então termos como "limites" e "gerações" passassem a estar constantemente presentes no léxico da problemática ecológica, como no título do 
seminal estudo econômico-ambiental do Clube de Roma intitulado "Limites do Crescimento" 5 , bem como na própria definição de desenvolvimento sustentável contida no Relatório Brundtland ("Nosso Futuro Comum") ${ }^{6}$, explicado como aquele que atente "as necessidades do presente sem comprometer a possibilidade de as gerações futuras atenderem as suas próprias necessidades"7. Afinal, quais os limites de uma tragédia como a de Mariana, que atinge as gerações presente e futura?

7 Assim, é justamente com a publicação do "Nosso Futuro Comum" que a concepção de desenvolvimento sustentável se tornou uma espécie modelo para o equacionamento entre economia e ecologia. Revoga-se as alusões ao natimorto "crescimento zero", defendido pelos países periféricos na Conferência de Estocolmo [1972], e ao utópico ecodesenvolvimento, da lavra de ideias que pretendiam ajustes mais severos no modelo de crescimento econômico, e se sistematiza uma noção que aproxima o neoliberalismo econômico com as virtudes dos investimentos ambientais. O modelo de desenvolvimento sustentável foi festejado como grande conquista geopolítica durante a realização da Conferência das Nações Unidas sobre Meio Ambiente e Desenvolvimento, no Rio de Janeiro, em 1992. Desde então, a inserção de vínculos com a concepção de sustentabilidade, em múltiplas escalas e temporalidades, tornou-se o leitmotiv de políticas públicas, investimentos e reestruturações produtivas de organismos empresariais e ações da sociedade civil. A construção do desenvolvimento sustentável, que envolve a gestão dos estoques de riquezas naturais dos países periféricos, a readequação do maquinário produtivo-industrial em escala global e a celebração ideológica de tais mecanismos como superação dos problemas ecológicos do mundo, tornou-se ponto pacífico.

8 Não é por outro motivo que cada vez mais empresas cada vez passaram a adotar medidas ambientais como forma de obtenção de lucros. Experiências de despoluição, de filtragem e de replantio se consolidaram e se tornaram uma marca de sucesso e dispositivos de marketing empresarial. Praticamente, mesmo causando toda a sorte de mazelas ambientais, toda empresa adota a sustentabilidade! Da mesma maneira, ajustes ambientais das cidades se tornaram uma tônica da urbanização pós-moderna, com a paulatina adoção de arquitetura ecológica, formas de tratamento e reutilização de água e coleta seletiva de lixo, ainda que muitas vezes mais na virtualidade. Seja no mercado de carbono global, seja na valorização cotidiana dos produtos orgânicos, assistimos o fausto das ideias ambientalmente corretas.

9 Todavia, como previsto, este modelo de desenvolvimento não trouxe mudanças significativas no espólio da natureza; afinal, espécies reproduzidas em cativeiros, áreas de proteção ambiental, florestas artificiais, tudo isto não compôs nem algo próximo a uma revolução na relação sociedade-meio ambiente, assim como as experiências empresariais foram peremptoriamente implantadas de maneira seletiva. Seja pela própria inépcia das soluções propugnadas neste ambiente de neoliberalismo ambiental, seja pela potência crítica aos pressupostos do modelo, neste intermezzo de pouco mais de duas décadas a concepção de desenvolvimento sustentável deixou de representar uma solução muito bem-vinda para os problemas ecológicos mundiais para ser objeto de desconfiança. Apesar de sua capacidade sedutora, sua ineficácia conjugada ao fato de sua implementação, mesmo quando celebrada como case de sucesso, não ter implicado em profundas mudanças no estatuto da natureza para o capital, tornou-se paulatinamente uma obviedade para todos. 
10 Mesmo assim, deveria causar espanto que ao mesmo tempo em que ocorre a descoberta de que os impactos da poluição são mais profundos, duradouros e nocivos, assistimos um recrudescimento da defesa ambiental. A constante relativização midiática da tragédia de Mariana, como veremos à frente, assim como o ataque reincidente às reservas ambientais, indígenas e quilombolas, sempre tratadas como obstáculos ao desenvolvimento por diferentes sujeitos políticos e econômicos; a construção recente de megabarragens, como a da Usina de Belo Monte na bacia do Rio Xingu, no sudoeste do estado Pará; os desacordos do clima liderados pelo Sr. Donald Trump, presidente dos Estados Unidos da América, são exemplos cabais de que a sustentabilidade já esteve mais em voga.

11 A aprovação do Projeto de Lei 6.299/02, que substituiu o uso termo "agrotóxico" por "defensivo fitossanitário" e amplia as possibilidades de utilização de tais venenos na agricultura brasileira ${ }^{8}$ confirma $o$ atual retrocesso ambiental. Nesta verdadeira "agrotoxicultura made in Brazil", há dúvidas para o leitor crítico se os maiores desalentos interpretativos são frutos das defesas hipócritas de que o uso dos pesticidas permitiria a ampliação do abastecimento de alimentos em larga escala ou a própria inépcia de certos defensores relativizando os malefícios do uso de venenos nas grandes plantações nacionais. É o advento de uma "primavera silenciosa" omni tempore, para lembramos do aviso de Rachel Carson feito em 1962, referente ao emudecimento desta estação do ano pela morte dos pássaros resultado do uso de diclorodifeniltricloroetano9.

12 Afinal, tais acontecimentos permitem afirmar que assistimos o advento de um modelo desenvolvimento pós-sustentável? Antes de mais, vale esclarecer que entendemos que a Geopolítica do Desenvolvimento Sustentável está alicerçada em três pressupostos centrais: [i] gestão protocolar da natureza-território dos países periféricos; [ii] ajuste econômico-produtivo para uso mais racionalizado da natureza enquanto recurso; e [iii] ideologia potente capaz de amalgamar interesses em prol de algo com aparência de bemcomum. Como geopolítica e ideologia, o desenvolvimento sustentável apresenta maleabilidade adaptativa, podendo adequar-se a diferentes modelos políticos, econômicos, sociais e mesmo ambientais.

13 Destarte, torna-se possível alentar que vivemos o aprofundamento do modelo! De um lado, aprimora-se a "Economia Verde", que implica no paradigma do desenvolvimento sustentável assumir sua face verdadeiramente econômica e com perspectivas de lucro de maneira mais agressiva - a Rio + 20, realizada em 2012, foi a consagração do desenvolvimento sustentável e consolidação do binômio economia-ecologia sob o manto desta terminologia ${ }^{10}$. Permanecem, assim, as virtudes da adoção do meio ambiente como estratégia de lucro e marketing. De outro lado, a racionalização do uso da natureza e a gestão das riquezas nos países periféricos ganham novos formatos em tempos de crise: promulga-se a superutilização da natureza-recurso em suas diversas formas sob os auspícios de novas tecnologias e amplia-se a necessidade novos acordos internacionais mais elásticos e com perspectiva menos protetiva e incisiva. Outrossim, os retrocessos desse processo em curso permitem, em última instância, a reabilitação do desenvolvimento sustentável como concepção avant-garde na construção de uma sociedade ambientalmente mais justa. O discurso "anti-meio ambiente" presente nos discursos de algumas lideranças políticas atuais reforça, em última instância, o desenvolvimento sustentável como opção econômica e política. 


\section{A geografia de um desastre e as lições de uma tragédia}

14 Três anos após o rompimento da barragem do Fundão, os impactos socioambientais ainda são sentidos pelas diferentes populações atingidas pelo desastre. Entre problemas com indenizações e reconstrução da vida em outro sítio urbano, em meio as águas poluídas do Rio Doce e as marcas da lama na paisagem, as marcas territoriais persistem no cotidiano daqueles que foram diretamente atingidos. É por meio de um esforço à luz da geografia que é possível construir algumas lições deste triste episódio ambiental brasileiro e mundial.

\section{Os desastres econômico-ambientais na contemporaneidade}

No dia 5 de novembro de 2015, a cidade histórica de Mariana, que fez parte da Estrada Real criada ainda no século XVII, foi o cenário principal do maior desastre ambiental da História do Brasil, de acordo com o Ibama. Foram 62 milhões de metros cúbicos de rejeitos despejados pelo rompimento da barragem do Fundão, equivalentes a dez lagoas Rodrigo de Freitas. Em apenas 12 segundos, foi devastado o distrito de Bento Rodrigues, vizinho à barragem local, que teve cerca de $80 \%$ de suas 257 construções destruídas.

Primeira Lição: Não bastassem os limites da técnica e da própria ação humana em escala planetária, a negligência das empresas e dos governos ainda é o maior problema ambiental contemporâneo.

Problemas desta natureza possuem "nome" e "sobrenome" e não podem ser classificados como acidentes. Entre e negligência e a inépcia, não é possível dizer tão somente que o "Desastre de Mariana" é fruto da índole do "homem moderno", senhor e possuidor da natureza transformada em recurso. Se trata, indubitavelmente, da inconsequente relação de empresas e governos para com as riquezas naturais, que requerem minimamente maio regulação e adequação de suas ações.

\section{A privatização do território e a "financialização"11 da natureza}

A Samarco Mineração S.A. é uma mineradora brasileira fundada em 1977, controlada por uma joint-venture da Vale S.A. e da BHP Billiton. Trata-se de uma empresa que lucrou R\$ 13,3 bilhões entre 2010 e 2014. Por sua vez, a HP Billiton, criada em 2001 pela fusão da australiana Broken Hill Proprietary Company Limited (BHP) e da anglo-holandesa Billiton, é uma mineradora e petrolífera multinacional sediada em Melbourne, Austrália. Em 2013, era a maior empresa de mineração do mundo em termos de receitas.

19 A Vale, renomeação da Companhia Vale do Rio Doce - CVRD [privatizada em 1997], é uma mineradora multinacional brasileira. É uma das maiores empresas de mineração do mundo e também a maior produtora de minério de ferro. A empresa participa em consórcios e atualmente opera nove usinas hidrelétricas[9], no Brasil, no Canadá e na Indonésia, além da liderança na área de logística no Brasil.

Segunda Lição: Segundo Milton Santos, em “A Natureza do Espaço” (1996), vivemos sob a égide do "território nacional da economia internacional". Que se reforce: quando se privatiza uma 
empresa de "infraestrutura" ou uma "indústria de base", também se privatiza o território nacional e se redimensionam as relações sociais e ambientais em múltiplas escalas.

\section{Uma tragédia em múltiplas territorialidades}

21 O desastre de Mariana não ficou restrito apenas ao estado de Minas Gerais. A lama atingiu cidades do Espírito Santo e o litoral Sul da Bahia. Ao todo, 39 cidades foram afetadas e 11 toneladas de peixes foram mortos ${ }^{12}$. Ecossistemas e espécies que já eram ameaçadas por atividades predatórias e impactos da indústria, agricultura e mineração, passaram a correr sério risco de extinção. Devido à extensa área atingida, a fauna e a flora do Rio Doce ficaram ainda mais vulneráveis: De acordo com o pesquisador Marcos Freitas, do Instituto Virtual Internacional de Mudanças Globais, e que participa do Grupo de Recomposição da Bacia do Rio Doce, serão necessários anos ou possivelmente décadas para a recuperação da bacia ${ }^{13}$.

Terceira Lição: A questão ambiental contemporânea é geograficamente desterritorializada, pois não somente extravasa as fronteiras [geo]políticas como também concatena diferentes ecossistemas em seus impactos. Pensar a questão ambiental contemporânea pressupõe repensar os significados de "fronteira", "território" e "política".

\section{A relativização do desastre: a vitória do "homem-estatística"}

23 A maior tragédia ambiental do Brasil deixou, no rastro do mar de lama que se espalhou por 650 quilômetros entre Minas Gerais e Espírito Santo, 19 mortos, a localidade de Bento Rodrigues (em Mariana) submersa, as de Paracatu de Baixo (também em Mariana) e Gesteira (em Barra Longa) destruídas e perdas imateriais que continuam doendo em seus moradores. Desde então, segundo o jornal "O Estado de São Paulo" de 05 de novembro de 2017 , as festas religiosas, as partidas de futebol descomprometidas, o bate-papo com os vizinhos e o trabalho na roça se esvaíram ${ }^{14}$.

Quarta Lição:: Segundo Ruy Moreira, em “O Discurso do Avesso" (1987), quando transformado em estatística, cada ser humano é "numerificado" e tem-se o rompimento do sentido emocional da vida.

Torna-se muito mais doloroso quando apontamos que faleceram, por exemplo, o motorista de caminhão Sileno Narkievicius de Lima, de 47 anos, o operador de máquinas Marcos Xavier, de 42 anos, o motorista de caminhão-pipa na Integral Engenharia Vando Maurílio dos Santos, de 37 anos, e Pedro Paulino Lopes, de 56 anos, mecânico industrial e pai do mestrando em Geologia Fabrício Lopes. São todos trabalhadores que apenas cumpriam seu dever em busca de sobrevivência! Ou a senhora Maria Elisa Lucas, 60 anos, que estava pescando, ou ainda Emanuely Vitória, de 5 anos, que estava em casa, e Thiago Damasceno Santos, de 7 anos, que brincava na casa da avó. Que se reforce o valor de cada vida perdida no desastre!

\section{A suavidade das políticas compensatórias}

26 A legislação brasileira prevê um teto de $\mathrm{R} \$ 50$ milhões para multas desta natureza; assim, o Ibama aplicou 5 multas neste valor máximo, totalizando 250 milhões de reais. Em acordo como o Ministério Público Federal, a Samarco se comprometeu a realizar um pagamento de uma caução socioambiental de $\mathrm{R} \$ 1$ bilhão, alterado para $\mathrm{R} \$ 4,4$ bilhões em 
2016. Além disso, houve a assinatura de um Termo de Transação de Ajustamento de Conduta $^{15}$.

A criação da em março de 2016 da Fundação Renova, entidade não-governamental privada e sem fins lucrativos, teve como objetivo reparar os danos causados pelo rompimento da barragem de Fundão, ocorrido em novembro de 2015 nas instalações da mineradora Samarco. Entre as críticas à fundação, estão os locais escolhidos para reassentar quem perdeu sua casa no desastre por serem áreas de risco e violação de direitos humanos das comunidades atingidas, dificultando o acesso às indenizações e aos auxílios emergenciais para as pessoas que tiveram as atividades econômicas inviabilizadas.

Quinta Lição: EIAs (Estudos de Impacto Ambiental), RIMAs (Relatórios do Estudo de Impacto Ambiental), TACs (Termos de Ajustamento de Conduta) e outros protocolos de ordem ambiental se tornaram insuficientes e frágeis perante a hegemonia dos interesses políticos e econômicos. A burocratização do modelo brasileiro reforçou seu estado falimentar da atualidade.

\section{A reabilitação ideológica da fábrica e a vitória do desenvolvimento}

Vivemos, de um lado, a emersão da "economia verde", que implica no paradigma do desenvolvimento sustentável assumir sua face verdadeiramente econômica e com perspectivas de lucro de maneira mais agressiva. Permanecem, assim, as virtudes da adoção do meio ambiente como estratégia de lucro e marketing. De outro lado, assistimos a racionalização do uso da natureza e a gestão das riquezas com novos formatos em tempos de crise: promulga-se a superutilização da natureza-recurso em suas diversas formas sob os auspícios de novas tecnologias e amplia-se a necessidade novos acordos internacionais mais elásticos e com perspectiva menos protetiva e incisiva.

Este modelo está combinado com uma espécie de proletarização extemporânea e seletiva, segregação e isolamento do cotidiano urbano em "fábricas-territórios", adequação econômico-ambiental sob os auspícios do desenvolvimento sustentável e reabilitação da fábrica como ideologia espacial. o desenvolvimento, em sua forma mais tradicional de "crescimento econômico" e "modernização tecnológica", se revigora na atualidade.

Sexta Lição: A reabilitação da chaminé como símbolo do desenvolvimento em alguns discursos políticos não permite tentar explicar sem reservas a realidade presente. 0 problema nunca foi o "sustentável", mas o uso do termo "desenvolvimento". O meio ambiente corre perigo: vivemos, decididamente, tempos sombrios.

\section{Considerações Finais: Pela repolitização da natureza!}

O debate acerca do conceito de desenvolvimento permanece urgente e inadiável; refletir sobre esta verdadeira fortaleza teórica que todos desejam, poucos questionam e que é processo e fim em si mesmo é ainda um grande desafio do tempo presente. Mais que suspeitar da concepção de desenvolvimento sustentável construída em estudos patrocinados por grandes corporações e em conclaves que reverberaram as imposições centro-periferia no âmbito da economia-política, é possível asseverar a necessidade de se demonstrar a incompatibilidade do modelo de desenvolvimento sustentável com verdadeiras mudanças na obliteração da natureza. A intenção é [sempre foi e permanecerá] democratizar a discussão - para além dos discursos prontos construídos em altos círculos 
de poder! -, para que possamos não somente desmistificar o desenvolvimento sustentável, mas contribuir para a crítica ao desenvolvimento, estandardizado como propósito do sistema vigente, e as suas adjetivações inócuas tão habituais na atualidade.

Eis a oportunidade: retirar o meio ambiente das engrenagens produtivas e das masmorras do marketing empresarial e governamental e recolocá-lo entre as grandes questões políticas do presente! As lições de Mariana precisam atingir as gerações presente e futura. A "repolitização" da natureza poderá significar uma verdadeira e genuína transformação.

\section{BIBLIOGRAFIA}

CARSON, Rachel. Silent Spring. Boston [United States of America]: Mariner Books, 1962.

FOLADORI, Guillermo. Limites do Desenvolvimento Sustentável. Campinas, SP: Editora da UNICAMP, 2001;

HARVEY, David. O Neoliberalismo: História e Implicações. São Paulo, Edições Loyola, 2008.

HOBSBAWM, Eric J. Era dos Extremos: O Breve Século XX: 1914 - 1991. São Paulo: Companhia das Letras, 1994;

MEADOWS, Donella H.; MEADOWS, Dennis L.; RANDERS, Jørgen; BEHRENS, William W. The Limits to Growth: A report for the Club of Rome's project on the predicament of mankind. New York [United States of America]: Universe Books, 1972.

MOREIRA, Ruy. O Discurso do Avesso: para a crítica da geografia que se ensina. Rio de Janeiro: Dois Pontos, 1987.

OLIVEIRA, Leandro Dias de. Rio + 20 : Reflexões sobre geopolítica e ideologia. Espaço e Economia: Revista Brasileira de Geografia Econômica, n.․ 4, 2014. Disponível em: http:// journals.openedition.org/espacoeconomia/854.

PORTO-GONÇALVES, Carlos Walter. A Invenção de Novas Geografias. In: Programa de PósGraduação em Geografia - PPGEO. Território Territórios. Niterói / RJ: UFF/AGB, 2002.

SANTOS, Milton. A natureza do espaço: técnica e tempo, razão e emoção. São Paulo: Editora HUCITEC, 1996.

WORLD COMMISSION ON ENVIRONMENT AND DEVELOPMENT. Our Common Future: Report of the World Commission on Environment \& Development. Oxford, England, UK: Oxford University Press, 1987.

\section{NOTAS}

1. Ver: https://oglobo.globo.com/brasil/acidente-em-mariana-o-maior-da-historia-combarragens-de-rejeitos-18067899. Acesso em: 01º de novembro de 2018.

2. "Air pollution particles found in. mothers' placentas", em 16 de setembro de 2018. Disponível em: https://www.theguardian.com/environment/2018/sep/16/air-pollution-particles-found-inmothers-placentas. Acesso em: 16 de setembro de 2018. 
3. "First evidence of soot air pollution reaching the placenta found in London mothers, new study says", por Peter Stubley, em 16 de setembro de 2018. Disponível em: https:// www.independent.co.uk/news/health/air-pollution-pregnant-women-london-study-placentafirst-evidence-a8539861.html. Acesso em: 16 de setembro de 2018.

4. Entre os muitos trabalhos que reforçam esta asserção, podemos destacar: HOBSBAWM, Eric J. Era dos Extremos: O Breve Século XX: 1914 - 1991. São Paulo: Companhia das Letras, 1994; FOLADORI, Guillermo. Limites do Desenvolvimento Sustentável. Campinas, SP: Editora da UNICAMP, 2001; PORTO-GONÇALVES, Carlos Walter. A Invenção de Novas Geografias. In: Programa de PósGraduação em Geografia - PPGEO. Território Territórios. Niterói / RJ: UFF/AGB, 2002.

5. Meadows, Donella H.; Meadows, Dennis L.; Randers, Jørgen; Behrens, William W. The Limits to Growth: A report for the Club of Rome's project on the predicament of mankind. New York [United States of America]: Universe Books, 1972.

6. World Commission on Environment and Development. Our Common Future: Report of the World Commission on Environment \& Development. Oxford, England, UK: Oxford University Press, 1987.

7. Op. cit. [Versão Brasileira], 1988, p. 46.

8. Consultar: https://www.camara.gov.br/proposicoesWeb/prop_mostrarintegra? codteor $=1654426 \&$ filename=Tramitacao-PL+6299/2002.

9. CARSON, Rachel. Silent Spring. Boston [United States of America]: Mariner Books, 1962.

10. Ver: OLIVEIRA, Leandro Dias de. Rio + 20 : Reflexões sobre geopolítica e ideologia. Espaço e Economia: Revista Brasileira de Geografia Econômica, n.․ 4, 2014. Disponível em: http:// journals.openedition.org/espacoeconomia/854.

11. Termo inspirado na obra "O Neoliberalismo: História e Implicações”, de David Harvey (São Paulo, Edições Loyola, 2008).

12. Ver: https://acervo.oglobo.globo.com/em-destaque/maior-desastre-ambiental-do-brasiltragedia-de-mariana-deixou-19-mortos-20208009. Acesso em: 03 de novembro de 2018.

13. Ver: https://www.em.com.br/app/noticia/gerais/2015/11/18/interna_gerais,709205/ rejeitos-de-minerio-ameaca-amazonia-marinha.shtml. Acesso em: 03 de novembro de 2018.

14. Ver: https://brasil.estadao.com.br/noticias/geral,desastre-de-mariana-2-anos-em-busca-dapropria-historia-e-de-reparacao,70002072236.amp. Acesso em: 03 de novembro de 2018.

15. Ver: http://g1.globo.com/hora1/noticia/2015/11/acordo-preve-multa-de-r-1-bilhaomineradora-pelos-danos-em-mg.html. Acesso em: 04 de novembro de 2018.

\section{RESUMOS}

Este texto é resultado de uma conferência na I JUCONS - Primeira Jornada Universitária de Conflitos Socioambientais, no auditório do Pavilhão de Aulas Teóricas da UFRRJ - Universidade Federal Rural do Rio de Janeiro, campus Seropédica - Rio de Janeiro, em 05 de novembro de 2018. A partir do olhar crítico da Geografia, o objetivo deste artigo é apresentar lições dos fatos conhecidos a respeito do "Desastre de Mariana" (MG, 2015).

This text is the result of a conference at the I JUCONS - First Conference of Socio-Environmental Conflicts, at the auditorium of the Pavilhão de Aulas Teóricas of the UFRRJ - Universidade Federal Rural do Rio de Janeiro, Seropédica - Rio de Janeiro, on November 5, 2018. From the 
critical view of Geography, the objective of this article is to present lessons from the known facts about the "Disaster of Mariana" (MG, 2015).

Este texto es el resultado de una conferencia en la I JUCONS - Primera Jornada Universitaria de Conflictos Socioambientales, en el auditorio del Pavilhão de Aulas Teóricas de la UFRRJ Universidade Federal Rural do Rio de Janeiro, campus Seropédica - Río de Janeiro, el 5 de noviembre de 2018. A partir de la mirada crítica de la Geografía, el objetivo de este artículo es presentar lecciones de los hechos conocidos acerca del "Desastre de Mariana" (MG, 2015).

Ce texte est le résultat d'une conférence tenue à l'I JUCONS - Première conférence sur les conflits socio-environnementaux, à l'auditorium du Pavilhçao de Aulas Teóricas de l'UFRRJ Universidade Federal Rural do Rio de Janeiro, campus Seropédica - Rio de Janeiro, le 5 novembre 2018. Du point de vue critique de la géographie, l'objectif de cet article est de présenter les leçons tirées des faits connus sur la "Catastrophe de Mariana" (MG, 2015.

\section{ÍNDICE}

Mots-clés: Durabilité, Catastrophe de Mariana, Leçons sur l'environnement.

Keywords: Sustainability, Mariana disaster, Environmental lessons.

Palavras-chave: Sustentabilidade, Desastre de Mariana, Lições ambientais.

Palabras claves: Sostenibilidad, Desastre de Mariana, Lecciones ambientales.

\section{AUTOR}

\section{LEANDRO DIAS DE OLIVEIRA}

Pós-doutorando em Políticas Públicas e Formação Humana da Universidade do Estado do Rio de Janeiro (PPFH-UERJ), com supervisão do Prof. Dr. Floriano José Godinho de Oliveira, por intermédio do desenvolvimento do projeto "Estado, Políticas de Gestão e Território: Um estudo sobre o Oeste Metropolitano do Rio de Janeiro". Doutor em Geografia pela UNICAMP Universidade Estadual de Campinas, Mestre e Licenciado em Geografia pela UERJ - Universidade do Estado do Rio de Janeiro. Professor do Programa de Pós-Graduação em Geografia [PPGGEO / UFRRJ] e de Geografia Econômica e da Indústria do Departamento de Geociências da UFRRJ Universidade Federal Rural do Rio de Janeiro. E-mail: ldiasufrrj@gmail.com. 